\title{
Flap Surgical Reconstruction
}

National Cancer Institute

\section{Source}

National Cancer Institute. Flap Surgical Reconstruction. NCI Thesaurus. Code C127812.

The surgical transfer of tissue from one site to another while maintaining its own blood supply. 